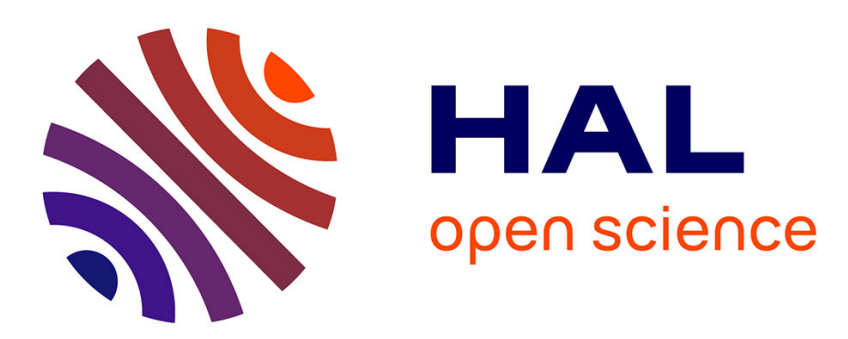

\title{
Conversion of cellulose to 2,5-hexanedione using tungstated zirconia in hydrogen atmosphere
}

Flora Chambon, Franck Rataboul, Catherine Pinel, Amandine Cabiac, Emmanuelle Guillon, Nadine Essayem

\section{To cite this version:}

Flora Chambon, Franck Rataboul, Catherine Pinel, Amandine Cabiac, Emmanuelle Guillon, et al.. Conversion of cellulose to 2,5-hexanedione using tungstated zirconia in hydrogen atmosphere. Applied Catalysis A : General, 2015, 504, pp.664-671. 10.1016/j.apcata.2015.02.042 . hal-01223684

\section{HAL Id: hal-01223684 \\ https://hal.science/hal-01223684}

Submitted on 3 Nov 2015

HAL is a multi-disciplinary open access archive for the deposit and dissemination of scientific research documents, whether they are published or not. The documents may come from teaching and research institutions in France or abroad, or from public or private research centers.
L'archive ouverte pluridisciplinaire HAL, est destinée au dépôt et à la diffusion de documents scientifiques de niveau recherche, publiés ou non, émanant des établissements d'enseignement et de recherche français ou étrangers, des laboratoires publics ou privés. 


\title{
Conversion of cellulose to 2,5-hexanedione using tungstated zirconia in hydrogen atmosphere.
}

\section{Flora CHAMBON ${ }^{1 *}$, Franck RATABOUL ${ }^{1}$, Catherine PINEL ${ }^{1}$, Amandine CABIAC ${ }^{2}$, Emmanuelle GUILLON ${ }^{2}$ and Nadine ESSAYEM ${ }^{1^{*}}$}

${ }^{1}$ Institut de Recherche sur la Catalyse et l'Environnement de Lyon, IRCELYON, Université Lyon 1, CNRS, UMR5256, 2 avenue Albert Einstein, F-69626 Villeurbanne, France. ${ }^{2}$ IFP Energies nouvelles-Lyon establishment, BP 3, F-69360 Solaize, France.

*Corresponding authors E-mail: nadine.essayem@ircelyon.univ-lyon1.fr

\begin{abstract}
:
2,5 hexadione is produced from cellulose using $\mathrm{ZrW}$ in the presence of hydrogen while lactic acid is the main product in helium atmosphere. FTIR and kinetics studies strengthened the proposed mechanism which involves as important elementary steps hydroxyls abstractions and hydride transfers promoted by the Lewis acid sites of ZrW. Moreover the important increase of cellulose conversion in the presence of $\mathrm{ZrW}$ in hydrogen atmosphere was explained by the likely formation of additional Bronsted acid sites formed by hydrogen interacting with $\mathrm{ZrW}$ which catalyze the protolysis of the glycosidic bonds in cooperation with the pool of hydroxonium ions provided by the self protolysis of water at $190^{\circ} \mathrm{C}$.
\end{abstract}

Key words: cellulose hydrolysis, solid acid catalysts, Lewis acidity, tungstated zirconia, , hydride transfer, 2,5-hexanedione 


\section{Introduction:}

For environmental and sustainable development concerns, researchers are doing a spectacular efforts in using renewable resources for the production of biofuels and platform chemicals, especially the lignocellulosic one due to its large availability and non-edibility. Cellulose, the main component of the lignocellulose is a biopolymer composed of glucose units linked by $\beta$ 1,4-glycosidic bonds which constitutes a material of choice since it is seen as a glucose reserve. Intermolecular and intramolecular hydrogen bonds existing in the crystalline network of the cellulose confers to it a high resistance to chemical conversion in conventional solvents [1]. However, it is known that hydrolysis of cellulose into sugars can be catalysed by strong mineral acids such as $\mathrm{H}_{2} \mathrm{SO}_{4}, \mathrm{HCl}$ and $\mathrm{HF}$. Because mineral acids are inexpensive, this method remains the most often used in research pilot development or in the few processes at industrial scale [2]. This method using liquid acids produces glucose but liquid acids cause corrosion and waste elimination remains problematic. Moreover, if acid hydrolysis conditions are severe (high temperature and/or concentration), a large fraction of sugars are degraded to undesired oligomers and tars. Later, enzymatic catalysis has been introduced with very selective cellulases for glucose production. However, these enzymes remain expensive and have still a rather low activity [2]. Recently, to try to overcome these drawbacks, other methods using heterogeneous catalysis in hydrothermal conditions appeared as an important breakthrough. From the pioneering works of Fukuoka in 2007, we can distinguish three main routes of cellulose transformation based on the nature of the bioproducts derived from glucose: hydrogenation, hydrogenolysis, or dehydration [3]. The first one is based on noble metals such as $\mathrm{Ru} / \mathrm{C}$ [4] or $\mathrm{Pt} / \mathrm{Al}_{2} \mathrm{O}_{3}$ [Erreur ! Signet non défini.] and leads to the formation of sorbitol directly from cellulose. The second routes produces shorter polyols in hydrogenolysis conditions, typically using transition metal catalysts and higher temperatures, i.e. ethylene glycol formation over $\mathrm{Ni} / \mathrm{WC}$ at $245^{\circ} \mathrm{C}$ [5]. The third one concerns the use of 
Brønsted acid catalysts such as sulfonated carbon [6,7,8] under milder conditions of temperature to give glucose and its derivatives formed via Brønsted acid catalized mechanism: 5-HMF and levulinic acid.

Beside these three main ways of cellulose transformation, a fourth one can be considered, using Lewis acids as catalysts to produce lactic acid in aqueous media [9] or lactate in alcoholic media [10]. In a previous study, we have shown that solid Lewis acids, such as tungstated alumina and tungstated zirconia, promote selectively the cellulose depolymerisation in lactic acid in water. We proposed that the solid Lewis acid sites intervene in cooperation with the pool of hydroxonium ions provided by the water selfprotolysis at $190^{\circ} \mathrm{C}$ to depolymerise selectively a crystalline cellulose in Lactic acid. The Lewis sites are proposed to promote C-C and C-O scissions via coordination of the hydroxyl groups of the soluble polysaccharides with the Lewis centers.

The present paper reports the influence of $\mathrm{H}_{2} / \mathrm{He}$ atmosphere on cellulose conversion using tungstated zirconia as catalyst in hot water $\left(190^{\circ} \mathrm{C}\right)$. Indeed, since noble metal free ZrW were previously reported to interact positively with molecular hydrogen in an acidic demanding reaction, alkane isomerisations in gas phase [11], we wanted to check if such interaction might occur in the aqueous medium and influence the cellulose conversion.

\section{Experimental section:}

\section{Tunsgtated zirconia synthesis}

Tungstated zirconia was prepared by anionic exchange between a tungstic acid (Aldrich) solution in hydrogen peroxide (Aldrich, $\mathrm{H}_{2} \mathrm{O}_{2} 30 \%$ ) and zirconium hydroxide according to a patented method [12]. Zirconium hydroxide was prepared by precipitation at $\mathrm{pH} 9$ with a zirconyl chloride solution $\left(\mathrm{ZrOCl}_{2} .8 \mathrm{H}_{2} \mathrm{O}\right.$, Aldrich) and ammonia solution $1.8 \mathrm{M}$. After 
agitation of the suspension for 20 minutes, the mixture was centrifuged and the precipitate washed several times with deionised water to remove chloride ions. The solid was then dried at $110^{\circ} \mathrm{C}$ for $24 \mathrm{~h}$. Then, $10 \mathrm{~g}$ of zirconium hydroxide were exchanged with the tungstic acid solution $(0.25 \mathrm{M})$ in hydrogen peroxide $(30 \%, 150 \mathrm{~mL})$ for 15 minutes. The exchanged solid was filtered and dried at $80^{\circ} \mathrm{C}$ for $24 \mathrm{~h}$. Finally, the solid was calcined at $700^{\circ} \mathrm{C}$ under air flow for $3 \mathrm{~h}$ [13]. The XRD pattern of $\mathrm{ZrW}$ shows the exclusive formation of the tetragonal $\mathrm{ZrO}_{2}$ phase as expected from the optimized method of preparation via anionic exchange [14]. The W loading and the BET surface area equal $11.8 \mathrm{wt} \%$ and $219 \mathrm{~m}^{2} \cdot \mathrm{g}^{-1}$ respectively.

\section{In situ FTIR studies}

FTIR spectra of self-supported pellets of ZrW were recorded with a Brucker Vector 22 spectrometer in the absorption mode with a resolution of $2 \mathrm{~cm}^{-1}$. The samples were placed in an IR cell equipped with $\mathrm{CaF}_{2}$ windows and treated in situ. The wafer of $\mathrm{ZrW}$ samples was first pretreated at $400^{\circ} \mathrm{C}$ under flowing oxygen for 2 hours. Pyridine vapor pressure was introduced in the cell for 15 min at ambient temperature and the $\mathrm{ZrW}$ pellet was desorbed at $150^{\circ} \mathrm{C}$ for 1 hour in order to remove the physisorbed pyridine species. Then 100 torrs of hydrogen were introduced in the cell at ambient temperature, and the $\mathrm{ZrW}$ pellet, previously saturated with pyridine, was treated at increasing temperature in $\mathrm{H}_{2}$ atmosphere. Finally, hydrogen was vacuum treated at ambient temperature, in order to compare the pyridine spectra before and after hydrogen treatment.

\section{Classical Batch experiments}

Untreated microcrystalline cellulose was purchased from Sigma-Aldrich and used as received (degree of polymerisation $=250$, crystalline index 70\%, particles size $20 \mathrm{~nm}$ ) . 
Reactions were performed in a $100 \mathrm{ml}$ Parr Hastelloy autoclave equipped with a Rushton turbide. The autoclave was filled with cellulose (1.6g), catalyst $(0.68 \mathrm{~g})$ and de-ionized water (65 ml). The autoclave was flushed three times with He at room temperature, and then heated up at $190^{\circ} \mathrm{C}\left(5^{\circ} \mathrm{C} / \mathrm{min}\right)$. The pressure was adjusted to $5 \mathrm{MPa}$ with $\mathrm{He}$ or $\mathrm{H}_{2}$ for 24 hours. The reaction was stopped by cooling the autoclave with an ice bath. The pressurized gas was evacuated, the reaction mixture was filtered and the liquid phase and the residual solid were collected.

\section{Kinetic experiments}

The Parr Hastelloy autoclave was connected to a $20 \mathrm{ml}$ stainless steel sampling vessel, pressurized with $\mathrm{He}$ or $\mathrm{H}_{2}$ at $5 \mathrm{MPa}$. Typically, the autoclave was filled with catalyst $(0.68 \mathrm{~g})$ and de-ionized water (48 ml). A suspension of cellulose ( $0.8 \mathrm{~g})$ in de-ionized water (18 $\mathrm{g}$ ) was introduced into the pressurized sampling vessel connected to the autoclave. The autoclave is flushed three times with $\mathrm{He}$ and then heated up to $190^{\circ} \mathrm{C}$. When the temperature is reached, the cellulose suspension in the sampling vessel is introduced into the autoclave under $5 \mathrm{MPa}$ of He or $\mathrm{H}_{2}$. This is the time zero of the reaction.

\section{Analytical methods}

The liquid phase was analyzed by a HPLC system with an ICE COREGEL 107H column (300mm x $\left.7.8 \mathrm{~mm}, 80^{\circ} \mathrm{C}\right)$ and a Refractive Index detector using acidified water as eluent (0.5 $\mathrm{mL} / \mathrm{min}, 0.01 \% \mathrm{~mol} \mathrm{H}_{2} \mathrm{SO}_{4}$ ). The liquid phase was also analyzed on a Shimadzu TOC-V $\mathrm{SCH}$ Total Organic Carbon (TOC) analyzer $\left(720^{\circ} \mathrm{C}, \mathrm{Pt} / \mathrm{Al}_{2} \mathrm{O}_{3}\right.$ catalyst, IR detector).

The solubilisation percentage, also defined as the conversion percentage, was calculated as the ratio of the total mass of carbon in the liquid phase obtained from TOC analysis and the initial mass of carbon in the charged cellulose: 
Conv $(\%)=$ Solubilisation $(\%)=100 *\left(\mathrm{mgC}_{\text {liquid phase }} / \mathrm{mgC}_{\text {initial cellulose }}\right)$

The carbon yields of the products detected by HPLC were calculated as the molar ratio of the product $i$ and the initial glucosyl units present in the initial cellulose, corrected by the number of carbon atoms:

Yield $_{\mathrm{i}}(\%)=100 *\left(\mathrm{nC}_{\mathrm{i}} / 6\right) *\left(\mathrm{n}_{\mathrm{i}} / \mathrm{n}_{\text {glucosyl units }}\right)$

$\mathrm{nC}_{\mathrm{i}}$ : number of carbon atoms in the product $\mathrm{i}$

$\mathrm{n}_{\mathrm{i}}$ : number of moles of the product i determined by the HPLC analysis

$\mathrm{n}_{\text {glucosyl units }}$ : initial number of moles of glucosyl units in the cellulose sample $=\mathrm{m}_{\text {cellulose }} / 162$

The yield of soluble oligosaccharides and polymers (SOP) was deduced from the difference between the conversion and sum of the yields of products analysed by HPLC:

Yield $_{\text {SOP }}(\%)=\operatorname{conv}(\%)-$ Syield $_{i}(\%)$

\section{Results and discussion}

\subsection{Influence of hydrogen or helium atmosphere on the cellulose conversion over ZrW}

The results of cellulose conversion at $190^{\circ} \mathrm{C}$ for 24 hours under hydrogen or helium atmosphere in the presence or absence of $\mathrm{ZrW}$ was summarized in Table 1. Blank experiments, done without solid catalysts and under $\mathrm{H}_{2}$ or $\mathrm{He}$, are very close and lead to cellulose conversions of $31-32 \%$ without any selective formation of chemicals. When the reaction was performed using $\mathrm{ZrW}$, under He atmosphere, a lactic acid yield of $18.5 \%$ was obtained with a cellulose conversion of 35\%. Beside, under hydrogen, in the presence of ZrW, the cellulose conversion was raised to $65 \%$, together with yields of $14 \%$ in lactic acid and of $24 \%$ in 2,5 -hexanedione, a product rarely reported to our knowledge. 2,5-hexanedione was identified by GC-MS (S1: supplementary information). A comparative experiment, performed with $\mathrm{W}$ free $\mathrm{ZrO}_{2}$, lead to limited yields in lactic acid and 2,5-hexanedione, 4\% of each, but the cellulose conversion was enhanced by $10 \%$ compared to the blank experiments. 
These results highlight that hydrogen atmosphere have a remarkable promoting effect on the rate and on the selectivity of cellulose reaction in the presence of tungstated zirconia. Thus, these data strongly suggest that the Lewis acid centres provided by $\mathrm{W}$ atoms, which were previously identified as the active centres responsible for lactic acid formation [9] could be also involved in the formation of the 2,5 hexanedione in the presence of molecular hydrogen.

\subsection{FTIR studies of hydrogen-ZrW Lewis acid sites interactions.}

The influence of the hydrogen atmosphere was evaluated by FTIR spectroscopy in gas phase assuming that if a peculiar interaction exist in the gas phase this might hold true in the liquid phase. Thus, we studied the interaction of the Lewis acid centres with molecular hydrogen after saturation of dehydrated $\mathrm{ZrW}$ sample with pyridine and subsequent evacuation at $150^{\circ} \mathrm{C}$ for $1 \mathrm{~h}$ to remove the physisorbed pyridine species. Thereafter, hydrogen was introduced in the IR cell and the temperature was increased stepwise to $250^{\circ} \mathrm{C}$.

Pyridine adsorption on $\mathrm{ZrW}$ resulted in the appearance of bands (Fig.1-a) due to pyridine adsorbed on Lewis sites $\left(1445 \mathrm{~cm}^{-1}\right)$ and Brønsted acid sites (1538 and $\left.1643 \mathrm{~cm}^{-1}\right)$. Upon hydrogen introduction and further temperature increase, the band due to pyridine coordinated to the Lewis sites at $1445 \mathrm{~cm}^{-1}$ was shifted to $1440 \mathrm{~cm}^{-1}$, wavenumbers value rather ascribed to physisorbed pyridine, in good agreement with the formation of new bands in the range 1550-1650 $\mathrm{cm}^{-1}$. Evacuation of $\mathrm{ZrW}$ at $150^{\circ} \mathrm{C}$ after hydrogen introduction (Fig.1.e) led to the disappearance of the previous bands, and to a decrease of the intensity of the Lewis band at $1445 \mathrm{~cm}^{-1}$ and a parallel increase of the intensity of the Brønsted band at $1643 \mathrm{~cm}^{-1}$ although the most characteristic vibration of the pyridinium species at $1538 \mathrm{~cm}^{-1}$ remained almost unchanged. Nevertheless, these IR results have shown that molecular hydrogen have modified the Pyridine IR spectra. This might indicate that molecular hydrogen interacts directly with the Lewis acid sites of $\mathrm{ZrW}$ but this could also results from a slight reduction of the $\mathrm{W}$ 
species. Note that in situ formation of Brønsted acid sites ascribed to slight reduction of WOx domains was already suggested by some authors [15] but this was also denied by others [16]. This issue remains controversial.

The observed increase of the cellulose conversion under hydrogen atmosphere compared to helium could be correlated, in a simple way, to in situ formation of new Brønsted sites from hydrogen heterolytic splitting promoted by ZrW. However, if such a phenomenon might intervene and explain the increase of the cellulose conversion, it does not explain the product distribution changes observed on $\mathrm{ZrW}$ when helium was replaced by hydrogen.

\subsection{Kinetic studies: mechanism pathways proposition}

The products of cellulose conversion obtained in the previous batch experiments, after $24 \mathrm{~h}$ of reaction, are the results of successive transformations. Over $\mathrm{ZrW}$ catalysts, in neutral atmosphere, lactic acid formation is favoured, while under hydrogen, the selectivity shifts towards 2,5-hexanedione. This peculiar behaviour in term of selectivity as a function of the reaction atmosphere $\left(\mathrm{He}\right.$ or $\left.\mathrm{H}_{2}\right)$ is not straightforward.

To address this issue several kinetic experiments were carried out in the presence of $\mathrm{ZrW}$ under hydrogen or helium atmosphere.

Figures 2 and 3 presents the kinetic results showing the evolution with time of cellulose conversion and of the main products yields: lactic acid, 2,5-hexanedione, acetol, 5-HMH, carboxylic acids. In a general rule, the higher selectivity of the main products, lactic acid, acetol or 2,5-hexanedione, is observed initially whatever the conditions employed. This could indicate either they are primary products or that the disappearance rate of eventual intermediary primary products is high.

First of all, we can observe that the cellulose conversion is largely improved in the presence of the solid Lewis acid ZrW in the presence of hydrogen as well initially than after 30 hours 
of reaction ( Fig.2a , S2). ZrW used in hydrothermal conditions and under hydrogen leads to an initial rate of cellulose conversion increased by one fourth compared to the blank experiment (Table 2) and to a cellulose conversion of $72 \%$ after 30 hours of reaction. To explained this initial enhancement of the initial rate we can propose, based on the previous FTIR studies, that hydrogen contacting ZrW might provide supplementary protonic acidity which might participate, in cooperation with the self protolysis of water, to the cellulose hydrolysis in hot water [17]. In the blank experiment, after 8 hours of reaction, we can observe that the cellulose conversion achieve $40 \%$ (S2) and looking to the product yields (S3), no product is formed with a selectivity higher than $6 \%$ after $30 \mathrm{~h}$ of reaction. One can also remark that the sum of the yields of products detected by HPLC represents roughly $50 \%$ of the cellulose conversion (S2), indicating than half of the product are soluble oligomers (humins), not detected by HPLC.

The presence of $\mathrm{ZrW}$ under helium atmosphere does not increased the cellulose conversion but has improved the selectivity of the transformation since the sum of the yields of products detected by HPLC are equivalent to the cellulose conversion determined by TOC analysis (Fig. 2a). This indicates that humins formations are suppressed as regards to the blank experiment (S2). Fig. 2b clearly shows that ZrW catalyst has a strong impact on the reaction selectivity: the high selectivity towards lactic acid is observed all along the transformation (Fig. 2b), the lactic acid yield continuously increases with the reaction time and achieves $20 \%$ after $30 \mathrm{~h}$ of reaction. Note, that initially the yield in 5-HMF equals that in lactic acid but with the course of the reaction, lactic acid becomes the dominant products, the yields in other products remain below 5\% (levulinic, formic,acetic acids, acetol, 5-HMF and pyruvaldehyde). As previously proposed [9], it seems that the presence of a solid Lewis acid in the reaction medium limits further transformations of the first oligosaccharides issued from the cellulose depolymerisation in humins, process catalyzed by the pool of hydroxonium ions provided by 
water self-protolysis. Accordingly, the first soluble species are proposed to be coordinate to the Lewis acid sites at the surface of the catalyst, and could undergo successive transformation steps leading to the selective formation of lactic acid.

It is proposed that solid Lewis acid sites could coordinate hydroxyl function groups, and provide carbocations at the catalyst surface by deshydroxylation. We propose that this is the driving force to convert selectively cellulose in lactic acid in hydrothermal conditions as previously suggested [9].

According to the above results, the following mechanisms are suggested (Scheme1):

We can propose that a Lewis acid site could coordinate the primary hydroxyl function of a glucose unit at the reductive end of a soluble oligosaccharide chain (Scheme 1, (3)). The protolysis of the glucosidic bond provides a glucose unit coordinated to a superficial Lewis center (4). Then, this could lead to a pull of $\mathrm{OH}^{-}$species, giving a primary carbocation on the C6 carbohydrate (5) and a superficial specie $\mathrm{OH}^{-} \square \mathrm{L}$. This intermediate (5) could be stabilized by intramolecular hydride transfer to give specie (6) (primary to tertiary carbocation). Then a $\beta$-scission could produce the 3 carbons intermediates (7a and 7b).

The specie 7a could lead to acetol (8) formation via keto-enolic equilibrium. Attack of the superficial specie $\mathrm{OH}^{-} \square \mathrm{L}$ could also produce lactic acid (9). Furthermore, the specie 7b could undergo a successive chain mechanism giving formation of pyruvaldéhyde (10) or via $\beta$ scission and attack of superficial specie $\mathrm{OH}^{-} \square \mathrm{L}$, the formation of formic acid (12) and acetic acid could be explained.

The most efficient catalytic system, not only on the initial rate of cellulose conversion but also on the final cellulose conversion, is $\mathrm{ZrW}$ used under hydrogen atmosphere. Indeed, in these conditions, the initial rate of cellulose conversion is increased by one fourth as regards to the blank experiment (Table 2) and the final cellulose conversion reached $65 \%$ in the batch 
experiment while, under $\mathrm{He}$, the cellulose conversion is roughly two times lower. As proposed above, this can be explained by the additional formation of Brpnsted sites due to the interaction of hydrogen with the Lewis acid centers but we can not exclude that the coordination of the reductive end of the first soluble oligosaccharide by the Lewis center might shift the cellulose solubilisation equilibrium.

Concerning the evolution of the products with time (Fig.2b), we can observe high initial selectivities in acetol and in a lesser extent in lactic acid and 2,5-hexanedione, formic acid and pyruvaldehyde. After 30h of reaction, 2,5-hexadione and acetol became the main products.

To rationalize the kinetic data observed for cellulose conversion over $\mathrm{ZrW}$ in the presence hydrogen, we propose that fast hydride transfer steps induced by heterolytic cleavage of hydrogen interacting with the Lewis center of ZrW could account for the selectivity changes. Therefore Scheme 2 proposes a reaction mechanism including hydride transfer steps to explain the formation of acetol and 2,5-hexanedione in the presence of $\mathrm{ZrW} / \mathrm{H}_{2}$ system. As said previously, the first soluble oligosaccharides (1) are generated from cellulose hydrolysis catalyzed by the hydroxonium ions issued from water self-protolysis at $190^{\circ} \mathrm{C}$. The glucose unit at the reductive end of the first soluble oligosaccharide (2) could be coordinated via the primary hydroxyl group to the Lewis acid site of $\mathrm{ZrW}$ and undergo a chain mechanism as proposed in Scheme 2. The remaining oligosaccharide chain (3b) may undergo a fast hydride transfer step in the presence of $\mathrm{ZrW} / \mathrm{H}_{2}$ system (3b) and then produces a partially dehydroxylated polysaccharide end (4). This specie could undergo further classic protolysis steps and produce partially dehydroxylated C6 species (5).

Lewis acid sites of the solid catalyst could further coordinate specie (5) and remove the primary hydroxyl group to produce a primary carbocation (6) which rapidly give a more stable tertiary carbocation (7) after an intramolecular hydride transfer step. A $\beta$-scission of 
specie 7 could form 2,5-hexanedione (8) after several elementary steps. Further $\beta$-scission and hydride transfer steps on specie 7 could give acetol (9).

\section{Conclusions}

It is well known that the major barrier of cellulose conversion is its initial depolymerisation, i.e its resistance to hydrolysis in mild conditions. We have shown here that the system $\mathrm{H}_{2} / \mathrm{ZrW}$ increases by two fold the cellulose depolymerisation in hot water without loss of carbons in humins formation.

The action of solid Lewis acid catalyst on the cellulose transformation is proposed to be centered on the first soluble species generated by cellulose glycosidic bonds cleavage by the hydroxonium ions of aqueous media. Brønsted solid acid sites was proposed to boost the initial depolymerisation of cellulose while the presence of solid Lewis acid sites might shift the equilibrium via coordination of the first soluble species, which might prevent their evolution towards humins via a classical protonic chain mechanism. The interaction between solid Lewis acid sites and the soluble species led to the selective formation of lactic acid in absence of hydrogen: hydroxyl groups abstraction is proposed to be the driving force.

The addition of hydrogen in the medium has several interesting effects. It permits not only to raise the cellulose conversion but also to change the selectivity of the reaction toward 2,5hexanedione formation. $\mathrm{ZrW} / \mathrm{H}_{2}$ system is proposed to promote fast hydride transfer steps. Novel mechanism pathways have been proposed in this study, to highlight the conjugated effect of the aqueous media and the heterogeneous Lewis acid catalysis on the cellulose conversion proposed to catalyze two main elementary steps: hydride transfers and hydroxyls group abstraction. 
[1]”Biomass recalcitrance. Deconstructing the Plant Cell Wall for Bioenergy” M.E. Himmel, Blackwell Publishing Ltd, 2009.

[2] « Biorefineries-Industrial processes and products » B.Kamm, P.R.Gruber, M.Kamm Eds, Whiley 2006.

[3] A. Cabiac, E.Guillon, F.Chambon, C.Pinel, F.Rataboul, and N.Essayem Appl. Catal. A:General 402 (2011) 1-10

[4] C. Luo, S.Wang, H.C.Liu, Angew.Chem.Int.Ed. 46 (2007) 7636-7639.

[5] Na Ji, Tao Zhang, M.Zheng, A.Wang, H.Wang, X.Wang, J.G. Chen Angew.Chem. Int.Ed. 47 (2008) 8510-8513.

[6] A.Onda, T. Ochi, K.Yanagisawa, Green Chem. 10 (2008) 1033-1037.

[7] S.Suganuma, K. Nakajima, M. Kitano, D.Yamaguchi, H. Kato, S. Hayashi, M. Hara, J. Am.

Chem. Soc 130 (2008) 12787-12793.

[8] S.Van de Vyver, L. Peng, J. Geboers, H. Schepers, F. de Clippel, C.J.Gommes, B. Goderis, P.A.Jacobs, B.F. Sels, Green Chemistry 12(6) (2010) 1083-1089.

[9] F.Chambon, F.Rataboul, A. Cabiac, C.Pinel, E.Guillon and N.Essayem Appl. Catal.

B:Environnemental 105(1-2) (2011) 171-181.

[10] Martin Spangsberg Holm, Shunmugavel Saravanamurugan, Esben Taarning Science 328 (2010) 602.

[11] D.G.Barton, M. Shtein, R.D.Wilson, S.L. Soled, E. Iglesia, The Journal of Physical Chemistry B, 103 (1999) 630-640.

[12] F. Figueras, N. Essayem, C. Feche, S. Loridant, J. Palomeque, G. Gelbard G, WO 2004/004893.

[13] F. Figueras, N.Essayem, C. Feche, S. Loridant , J. Palomeque, G. Gelbard WO 2004/004893.

[14] PhD thesis, Cyril Feche, University Lyon 1, 2005.

[15] D.G. Barton, M. Shtein, R.D. Wilson, S.L. Soled, E. Iglesia, The Journal of Physical Chemistry B 103 (1999) 630-640.

[16] S.Kuba, P.Lukinskas, R.K. Grasselli, B.C. Gates, H. Knözinger, Journal of Catalysis, 219 (2003)376-388.

[17] V.Jollet, F.Chambon, F.Rataboul, A. Cabiac, C.Pinel, E.Guillon and N.Essayem

Green Chem 11 (2009) 2052-2060 
